passed through the cabinet and led away into a laboratory fume cupboard.

CONTRAST DEVELOPMENT IN THIN CRYOSECTIONS BY ELECTRON BEAM EXPOSURE AT LOW DOSE

P. H. H. Bomans and P. M. Frederik

Pathology, University of Limburg P. O. Box 616, 6200 MC Mastricht, The Netherlands

Cryo-electron microscopy of hydrated biological materials requires thin and vitrified specimens. For specimens that cannot be captured in thin films this implies that vitrified samples have to be sectioned on a cryo-ultramicrotome. Vitrification of pancreas samples was accomplished by infiltrating aldehyde-fixed samples in vitrifying concentrations of methanol (808), propylene glycol (808) or glycerol (678). According to the theories of contrast formation there should be an increasing electron opacity from methanol through glycerol of these aqueous embeddings. In our low-dose pictures of cryo-sections from vitrified pancreas samples no contrast has been observed in the "virgin" exposures; contrast developed gradually in consecutive exposures. This was confirmed for the three aqueous embeddings tested. In addition the development of contrast was monitored with a TV camera with an image intensifier. The video images show an appearance of contrast at an electron dose of ca. 1000 $\mathrm{e} / \mathrm{nm}^{2}$. The apparent anomaly in contrast of thin cryo-sections compared to thin vitrified films can only be explained by a larger contribution of multiple-scattered electrons to the image of cryosections. Our findings demonstrate a contrast-inducing effect of the electron beam, even at low dose conditions, on cryosections from infiltrated and vitrified pancreas samples.

HREM OF STACKING IRREGULARITIES IN CHLORITE CRYSTALS

A. J. Bons and D. Schryvers*

Instituut voor Aardwetenschappen, Rijksuniversiteit Utrecht, Budapestlaan 4, Utrecht, The Netherlands; * Rijksuniversitair Centrum Antwerpen, Groenenborgerlaan 171. Antwerp, Belgium

Chlorite crystals from slate rocks have been studied by high resolution electron microscopy. Chlorite is one of the most common phyllosilicates in natural rocks. The crystal structure is formed by alternating talc-like sheets, (Fe, $\mathrm{Mg}, \mathrm{Al})_{3}(\mathrm{SI}, \mathrm{Al})_{4} \mathrm{O}_{10}(\mathrm{OH})_{2}$, and brucite-like sheets $(\mathrm{Fe}, \mathrm{Mg}, \mathrm{Al})_{3}(\mathrm{OH})_{6}$.

(OO1)-lattice fringe images of chlorite $(\mathrm{d}=14 \AA)$ are characterised by a strong variation in intensity of the individual fringes. Deviating fringe spacings (78 and $9 \AA$ ) are also common. The nature of these irregularities has been investigated by HREM performed on a top-entry JEOL $200 C X$ electron microscope at the University of Antwerp (RUCA).

The variation in intensity of the lattice fringes can be explained by irregular shifts of the crystal lattice of magnitude $b / 3$ in directions parallel to (001). The HREM images, combined with computer simulations, show that these shifts can take place at two levels in the unit cell: (1) at the centre of the talc sheet and (2) at the brucite sheet.

The 98 fringes arise from layers where the brucite sheet is missing. The 78 fringes are caused by intercalations with a kaolinite structure.

THE ANALYTICAL SEM AND STEM, AN INDISPENSABLE TOOL IN CERAMICS RESEARCH

B. A. Boukamp, A. J. A. Winnubst,

$K$. Keizer, K. J. de Vries and

A. J. Burggraaf

University of Twente, P.O. Box 219 , 7500 AE Enschede, The Netherlands

The analytical scanning and (scanning) transmission electron microscopes are indispensable tools in the research field of advanced ceramics. The EMs are used for characterization and analysis at the various stages in the sample preparation procedure and beyond the final stage, in subsequent annealing and aging experiments. In this presentation the involvement of EM analysis in the ceramic materials research program of our laboratory is discussed.

In the development of tough ceramics based on tetragonal $\mathrm{ZY}$, the EM is used for monitoring the (precursor) powder particle sizes (about $10 \mathrm{~nm}$ ), the measurement of grain growth $(<0.5 \mathrm{mu})$ during the sintering process and change in morphology due to aging experiments. (Un) wanted second phase is characterized with EDS.

Microporous ceramic membranes consisting of one to three layers, with decreasing pore sizes, on top of a porous 
support, can be used for gas separation. These thin top layers (1-5 micron) are checked with the SEM for pinholes and cracks. The interface between two layers of different material is monitored with EDS.

Electro-ceramic materials (oxides) find use in solid oxide fuel cells, oxygen pumps and gas sensors. Grain size and unwanted second phases influence the ionic conductivity. The electrode kinetics are largely controlled by the electrode morphology. The SEM is the appropriate tool for the analysis of these aspects.

\section{RECRYSTALLIZATION MECHANISMS IN} OMPHACITE

M. Buatier, M.R. Drury and H.L.M. van Roermund*

Universite Louis Pasteur, 67084

Strasbourg, France; $R . U$. Utrecht, Budapestlaan 4, 3584 CD Utrecht, The Netherlands

Eclogites from the Sessia Lanzo zone of the Alps have been deformed at $T=500-$ $600^{\circ} \mathrm{C}$ and $\mathrm{P}=14-16 \mathrm{~kb}$. Microstructures in omphacite (Na-rich clinopyroxene) indicate that recrystallization has occurred by a rotation mechanism, where single crystals become polycrystals by the development of numerous internal high-angle boundaries. Most of the recrystallized grains contain well developed dislocation substructures, while a few are almost completely defect free.

Analysis of dislocation nodal points and walls indicate activity of the following slip systems <1IO>\{110\}, [001] $\{110\}$ and $[001](100)$. The dominant lowangle subboundaries are simple tilt walls parallel to $\{110\}$ with rotation axis [001] and (001) with rotation axis $\langle 110\rangle$. New internal high-angle boundaries have more general orientations with many close to $\{h k 0\}$. Rotation axes are also more dispersed with 308 close to [001] and 708 with general orlentation.

The results are consistent with the initial formation of most new grain boundaries by progressive misorientation of $\{110\}$ tilt walls. Dispersion of the boundary orientations can be explained by static grain boundary migration and dispersion of the rotation axes can be produced by activation of different slip systems on elther side of the newly formed grain boundary.
IMMUNOELECTRON MICROSCOPY OF NEUROTRANSMITTER MOLECULES WITH PRE- AND POST-EMBEDDING TECHNIQUES

R. M. Buijs

Netherlands Institute for Brain Research, Meibergdreef 33, $1105 \mathrm{AZ}$

Amsterdam, The Netherlands

The study of the ultrastructural 10calization of antigens in tissues is influenced by a great many factors. In selecting the proper tissue-processing procedure, attention has to be focused on the preservation of immunoreactivity as well as the tissue structure. However, every form of tissue processing, fixation, and embedding changes the identity of the tissue components, while in mildly fixed tissue the embedding or the long immunocytochemical (ICC) incubation procedures also harm the morphology. It is thus necessary to make a compromise, the final outcome of which largely depends on the aim of the ICC study (e.g. Which antigen needs to be localized, or the choice of light- or electronmicroscopical localization).

In EM studies, some loss of antigenicity is gladly taken in change for preservation of ultrastructure. In spite of the fact that in immuno-EM studies on, e.g., the adenohypophysis, $\mathrm{OsO}_{4}$ has been used successfully, the use of this fixative is generally accompanied by a loss of all immunoreactivity. This holds especially for larger molecules, which have groups like tyrosine that can easily react with $\mathrm{OsO}_{4}$, and for the catecholamines, the ring structure of which is easily lost. It appeared that for small amino acids, $\mathrm{OsO}_{4}$ fixation did not destroy the immunoreactivity. This is easily explained by the fact that $\mathrm{OsO}_{4}$ will not bind to or cannot oxidize these extremely stable molecules. Consequently, GABA immunoreactivity was demonstrated in glutaraldehyde-OsO4-fixed tissue embedded in plastic.

In conclusion, it will be clear that the success of the entire procedure depends on the reaction of the antibody to the fixed antigen.

A MORPHOLOGICAL APPROACH TO INFLUENZA VIRUS - MODEL MEMBRANE INTERACTION

Koert N.J. Burger, Gerhard Knoll* and Arie J. Verkleij** 